\title{
Scientific findings related to changes in vascular microcirculation using infrared thermography in the river buffalo
}

\author{
Aldo Bertoni - Daniel Mota-Rojas (D). Adolfo Álvarez-Macias • Patricia Mora-Medina (D). Isabel Guerrero-Legarreta (D).
} Armando Morales-Canela • Jocelyn Gómez-Prado • Nancy José-Pérez • Julio Martínez-Burnes (D)

\begin{abstract}
A Bertoni
Master's Program in Agricultural and Livestock Sciences (Maestría en Ciencias Agropecuarias), Universidad Autónoma Metropolitana (UAM), Xochimilco Campus, 04960, Mexico City, Mexico.

D Mota-Rojas (Corresponding author) - A Álvarez-Macias • J Gómez-Prado - N José-Pérez

Neurophysiology, behaviour and animal welfare assessment. Department of Animal Production and Agriculture, Universidad Autónoma Metropolitana, Xochimilco campus, Mexico City, Mexico.
\end{abstract}

email:dmota@correo.xoc.uam.mx

\section{P Mora-Medina}

Livestock Science Department, Universidad Nacional Autónoma de México (UNAM), Facultad de Estudios Superiores Cuautitlán, 54714, State of Mexico, Mexico.

\section{Guerrero-Legarreta}

Department of Biotechnology: Food Science. Emeritus Professor, Universidad Autónoma Metropolitana, Iztapalapa campus (UAM-I), 09340, Mexico City, Mexico.

\section{A Morales-Canela \\ Ciencias Agrícolas, Universidad EARTH, Guácimo, 70602, Costa Rica.}

\section{J Martínez-Burnes}

Graduate and Research Department, Facultad de Medicina Veterinaria y Zootecnia, Universidad Autónoma de Tamaulipas, Victoria City, Tamaulipas, Mexico.

Received: June 27, 2020 • Accepted: July 13, 2020 • Published Online: August 04, 2020

\begin{abstract}
The objective of this review article is to discuss and analyze the most important scientific findings from studies of vascular microcirculation in the river buffalo using infrared thermography (IRT), as well as the thermal windows utilized with this species. The goals are to define the scope and areas of opportunity for IRT use in evaluating physiological processes and identifying potential applications in reproductive events associated with andrological traits in males and the detection of estrus and udder health in females. IRT has allowed the development of diverse perspectives regarding the comparative physiology of events like thermogenesis, peripheral blood flow, respiratory physiology, and mechanisms that reduce body temperature. The case of the river buffalo is no exception. According to the information analyzed, the temperatures of the orbital area, muzzle, and vulva have proven efficient for evaluating thermal comfort, a particularly important aspect of this species given its limited thermoregulating capacity and constant exposure to extreme temperatures. Evaluating scrotal temperature has been revealed as an appropriate tool for evaluating semen quality, while the surface temperature of the udder is useful in assessing mammary development in female buffaloes, two aspects of great zootechnical importance. In future studies, IRT will play a fundamental role in enhancing our understanding of the river buffalo's mechanisms of vascular
\end{abstract}

microcirculation, with applications in productivity and behavior.

Keywords: Bubalus bubalis, buffalo welfare, heat dissipation, thermal behaviors, thermal changes, thermal stress, thermoregulation

\section{Introduction}

Both physiological events and environmental factors can alter blood flow and tissue vascularization, processes that can be reflected in the surface temperature of the skin due to its function as a cooling system that irradiates heat (Purohit et al 1985; Cravello and Ferri, 2008; de Ruediger et al 2018; Mota-Rojas et al 2020a). Several methods have been utilized to measure the temperature changes that different species present under distinct conditions, but most options available are invasive, opening the possibility that the changes observed may be affected by the stress generated in the animals during the maneuvers required (Clapper et al 1990; Mosher et al 1990; Redden et al 1993; Kyle et al 1998; Fisher et al 2008; Sevegnani et al 2016). However, the use of the non-invasive technology called infrared thermography (IRT) is increasing because this technique has the capacity to take precise measurements of the surface temperatures of certain corporal regions from a distance of $30 \mathrm{~cm}$ or more. IRT thus facilitates 
the identification of thermal alterations characterized by an increase or decrease of skin surface temperatures (Chacur et al 2016; Sevegnani et al 2016; Menegassi et al 2018; CasasAlvarado et al 2020; Bertoni et al 2020; Mota-Rojas et al 2020a; Guerrero-Legarreta et al 2020).

Infrared thermography has fostered the development of diverse perspectives on the comparative physiology of such events as thermogenesis, peripheral blood flow, respiratory physiology, and mechanisms for reducing body temperature (Tattersall and Cadena, 2010; Tattersall, 2016; Mota-Rojas et al 2020a). In veterinary medicine, it has been used to monitor and interpret temperature changes in animals caused by the environment (Mota-Rojas et al 2016), in different aspects of the human-animal relationship (Mota-Rojas et al 2020b; Napolitano et al 2019), during environmental enrichment to reduce stress (Orihuela et al 2018), in intensive and extensive systems (Mora-Medina et al 2018a), during allosucking (Mora-Medina et al 2018b), to evaluate animals' physiological responses to high temperatures (Knizkova et al 2007; Paim et al 2013; Mota-Rojas et al 2020a; Guerrero-Legarreta et al 2020), infrared thermal imaging associated with pain in laboratory animal (Mota-Rojas et a 2020c), to measure changes in vascular microcirculation during antemortem processes in stunning of pigs (Flores-Peinado et al 2020), to study skin temperature changes and evaluate mastitis in dairy cows (Colak et al 2008), to analyze changes in the locomotor system sof horses and ruminants (Alsaaod and Büscher, 2012; Stewart et al 2010), and to evaluate the effects of castration on pigs (Pérez-Pedraza et al 2018), among other phenomena. More recently, IRT has been employed to analyze the physiological, reproductive and health processes characteristic of the water buffalo (Bubalus bubalis), a species that has been successfully adopted into production systems in tropical regions thanks to its resistance to infectious and parasitic diseases (Angulo et al 2005; Barboza, 2011), and its excellent productive performance (Mota-Rojas et al 2019). For these reasons, the present review article set out to discuss and analyze the most important scientific findings in the study of vascular microcirculation in the water buffalo using IRT, and the thermal windows utilized with this species. Our objective is to define the scope and areas of opportunity for utilizing infrared thermography to evaluate physiological processes, and its potential application in reproductive events associated with andrological aspects of males, and the detection of estrus and the health of the udder in females.

\section{Thermal windows in the river buffalo}

Endothermic animals regulate their body temperature by equilibrating the amount of heat produced metabolically and through temperature exchanges with the environment (Tortora et al 2013). While this mechanism may involve any part of the animal's body, under certain circumstances specific regions possess characteristics that optimize heat exchange, perhaps due to a broad surface area, a rich vascular bed or, especially, the capacity to alter blood flow under different conditions. These regions are called 'biological thermal windows' (Romanovsky et al 2002; Andrade, 2015). One of the most oft-used windows is the ocular region, which offers key benefits like precision and consistency in the use of IRT. A study in bovines gender Bos, demonstrated that temperatures measured on the forehead mirrored rectal temperature better than readings taken on the flank, udder, rump, ears or cheek (Peng et al 2019). In female buffaloes -at least those raised in tropical humid environs- ocular and cheek temperatures correlate most positively and significantly with rectal temperature (Brcko et al 2020).

Other regions that have been used as thermal windows to evaluate changes in the surface temperature of buffaloes under diverse conditions include the orbital region, muzzle, flank, udder, vulva, and scrotum (Figures 1 and 2). However, temperature readings from these areas, and their efficacy as thermal windows, depends on the specific event analyzed, as the following paragraphs will show.

\section{Evaluating the surface temperature of buffaloes raised under tropical conditions}

One of the principal challenges that buffaloes face in tropical regions is exposure to extreme heat because their skin is black and has scarce hair, conditions that permit the absorption of large amounts of solar radiation. Moreover, the sweating capacity of this species is null. These characteristics leave the buffalo vulnerable to suffering thermal stress (Ruiz et al 2012; Kastelic, 2014; Mota-Rojas et al 2020a,c; Bertoni et al 2020), though performing behaviors like searching for shade and immersing in marshy zones allow these animals to quickly reduce their body temperature thanks to cutaneous blood vessels that efficiently conduct and irradiate heat (Aggarwal and Upadhyay, 2013).

Infrared thermography can be utilized to evaluate the impact of the performing these behaviors (Figure 2) and to assess the effect of tropical environments on the temperature in this species, as in the study by Barros et al (2016), who used 10 clinically-healthy, Murrah buffaloes bulls $(701.4 \pm 82.8 \mathrm{~kg})$ (Bubalus bubalis) to analyze the surface temperature of the orbital area, right and left flanks, and scrotum using IRT. Their goal was to correlate surface temperature with variations in bioclimatological indexes of thermal comfort (determined by rectal temperature and respiratory frequency), including evaluating the temperature and humidity index (THI), ICB, and Benezra's comfort index for buffaloes raised in regions with tropical climates. 

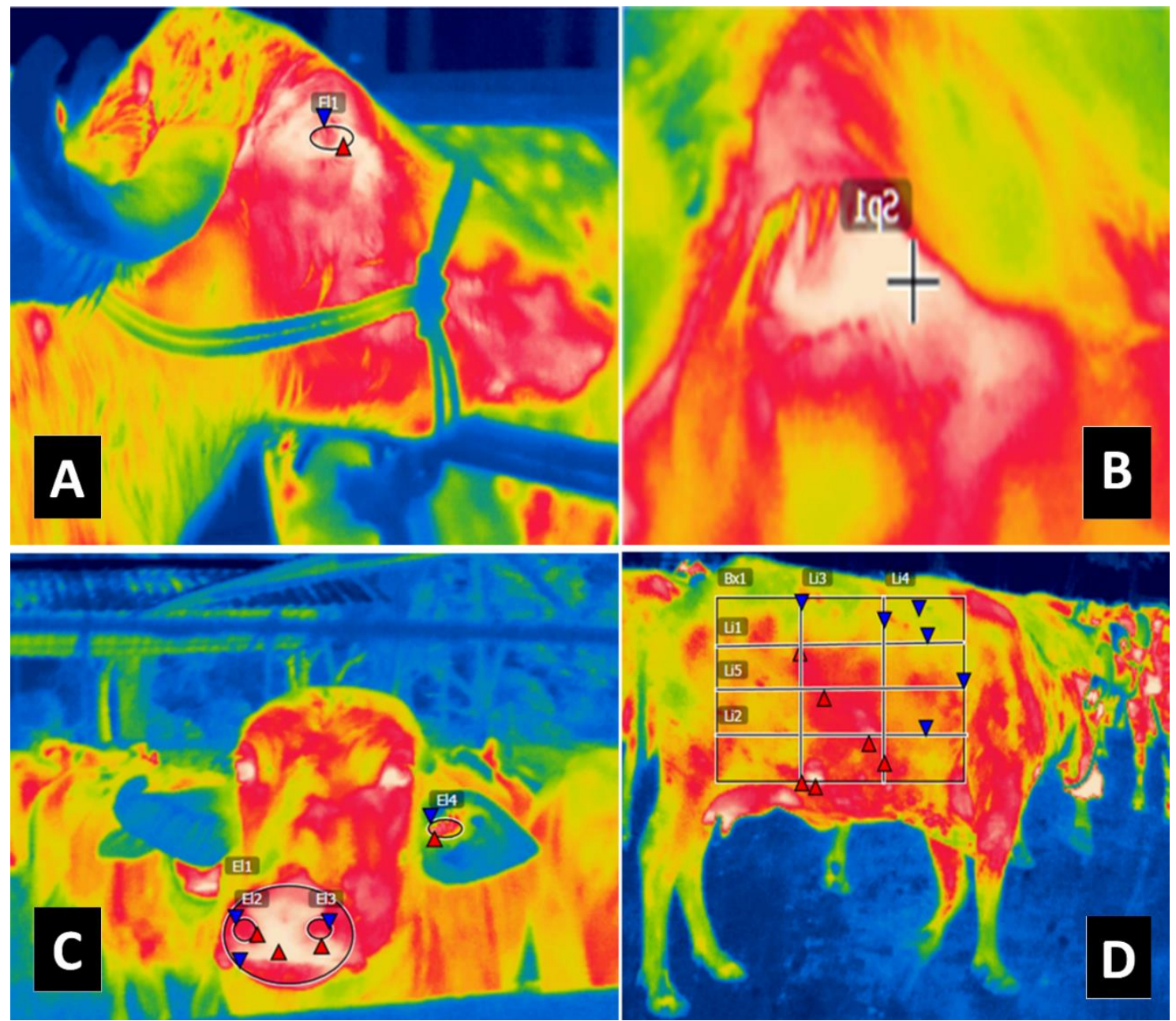

Figure 1 Periocular, lacrimal caruncle, muzzle, and lateral region thermal windows in the river buffalo. A) Periocular region. According to Barros et al (2016) and de Ruediger et al (2018), this region best reflects the rectal temperature and is least affected by a mbient temperature. In the thermogram obtained at an emissivity of 0.95 , this region is circled by an ellipse that spans the entire eyeball. B) Lacrimal caruncle. This is one of the areas most-extensively studied with IRT because it can be a good indicator of changes in body temperature attributed to the sympathetic responses of the autonomous nervous system (Travain et al 2015). In the thermogram, this area is signaled by a point placed in the center of the caruncle. C) Muzzle. According to de Ruediger et al (2018), the muzzle reflects the rectal temperature quickly and precisely and involves a less invasive procedure, so it can be used to study the thermal comfort of female dairy buffaloes. The thermogram shows three circles around the periphery of the muzzle with two marking the nostrils. It is important to mention that taking rostral thermographic images also makes it possible to evaluate oral temperature by placing an ellipse around the auricular pavilion. D) Lateral region. Barros et al (2016) point out that both the right and left flanks can be utilized as thermal windows if, for some reason, it is difficult to analyze the orbital region. This procedure, however, requires considering that the left flank presents an elevated preprandial temperature (Montanholi et al 2008). In the thermogram, this region is signaled by a checkered rectangle.

The best thermal window for evaluating the thermal condition of buffaloes is the orbital region because, as in observations of cows (Hoffmann et al 2013), the maximum surface temperature of this area (36.7 \pm 0.6$)$ is the measure that corresponds most closely to rectal temperature, since it suffers fewer maladjustments due to the effect of environmental temperature (Gloster et al 2011). However, one must consider that this particular window can present certain disadvantages; for example, the fact that the handler must approach the animal closely, which may require restraint, and that she/he should be careful not to approach too closely. The flanks are a useful option for obtaining information on an animal's thermal equilibrium when it is not possible to evaluate the orbital area, but this also requires basic care measures before measuring because the left flank is subject to pre-prandial temperature increases (Montanholi et al 2008). Regarding the scrotum as a thermal window $\left(33.3 \pm 1.1^{\circ} \mathrm{C}\right)$, it is important to consider that both temperatures -internal and environmental- exert effects on the scrotal surface due to the extracavitary position of the testicles and because the skin in this area is thin, hairless, and has numerous subcutaneous blood vessels that promote heat loss (Kastelic 2014).

The findings of Barros et al's study (2016) allow the inference that the orbital area, followed by the flanks, are efficient thermal windows for evaluating the thermal comfort of buffaloes in tropical areas where temperature and humidity are closely related. 

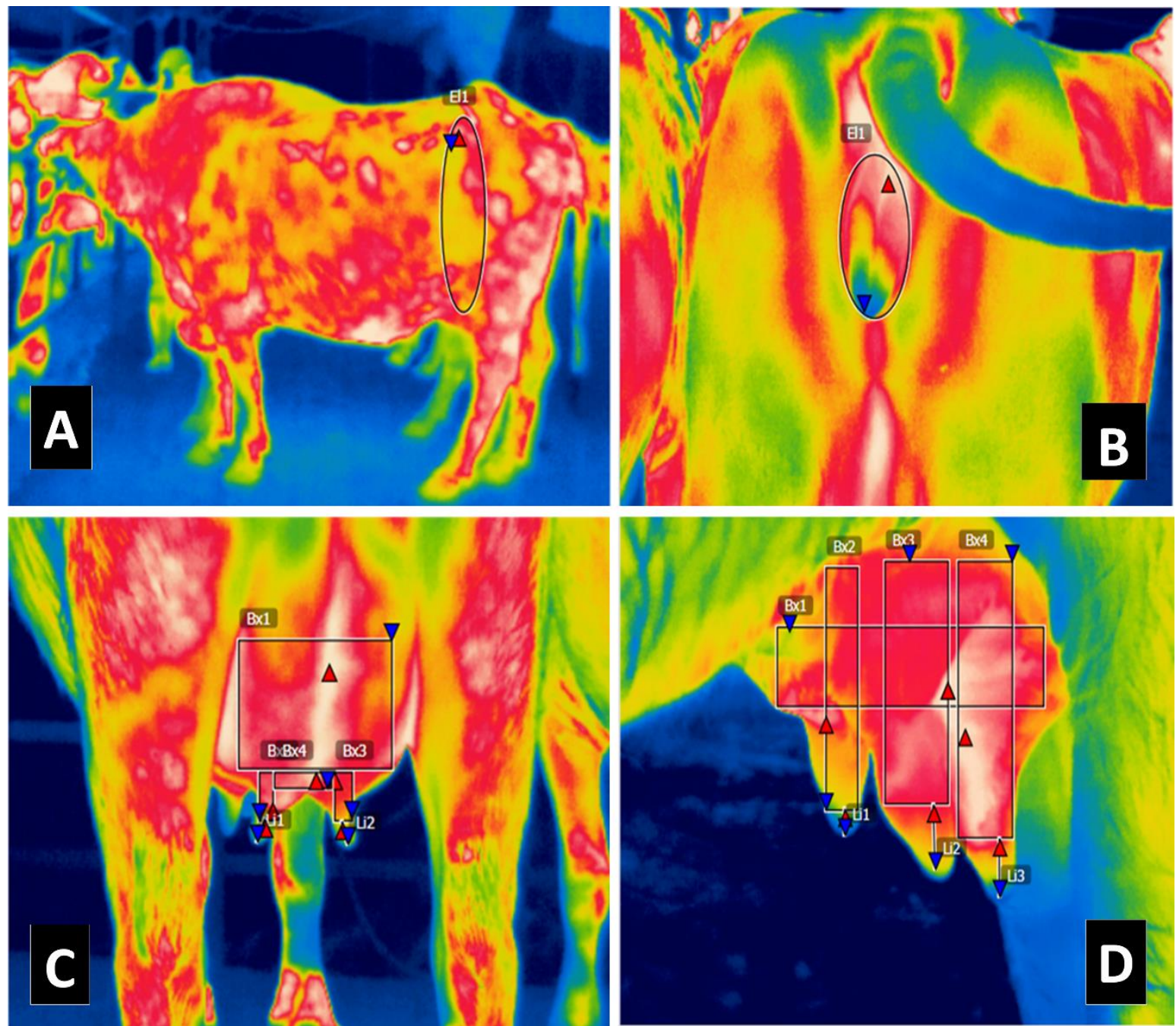

Figure 2 Thermal windows of the flank, vulva, and udder of the river buffalo. A) Flank. In the thermogram, this zone is circled with an ellipse. B) Vulva. According to the report by Barros et al (2016), the vulva is an excellent thermal window for determining the physiological changes inherent in the variations of progesterone concentrations during the female buffalo's reproductive cycle. In the thermogram, the periphery of the vulva is circled by an ellipse. C) Posterior udder. D) Lateral udder with teats.

\section{Andrological evaluations}

In the process of thermoregulation of the scrotal area, the testicular vascular cone (TVC) in the upper region of the testicles performs the function of countercurrent heat exchange to reduce the temperature of arterial blood before it enters the testicles. The importance of this effect is reflected directly in sperm viability because high testicular temperatures increase the probability of adverse effects on spermatogenesis that can alter motility, viability, and morphology (Kastelic et al 2018). In this regard, IRT has proven to be an efficient tool for identifying testicular damage caused by heat stress or acute inflammatory processes, both of which may be manifested in modifications of scrotal temperature (Menegassi et al 2018).

Based on the premise that thermography can be used to evaluate semen quality and the fertility of bulls raised for meat (Lunstra and Coulter, 1993), Yadav et al (2019) designed a study to evaluate the effect of (i) the scrotal surface temperature gradient (SSTG) (obtained by determining the difference between the temperature of the dorsal and ventral areas of the scrotum); (ii) the thickness of the testicular covering (TTC); and (iii) scrotal circumference, on the quality of the semen of 130 Murrah breeding bulls from distinct regions of India where maximum temperatures reached 40 $48^{\circ} \mathrm{C}$ in summer, and minimum temperatures were $1-4^{\circ} \mathrm{C}$ in winter. They used an infrared camera to measure the surface temperature of the scrotum of each buffalo one day before semen collection, ultrasonography to calculate the TTC of 38 buffaloes, and a tape measure to determine scrotal circumference. Although their results did not show any significant variation in ejaculation volume -likely because the accessory sex glands were not affected by temperature changes in the scrotum- the best motility $(3.73 \pm 0.08)$ and highest sperm concentrations $(1265.64 \pm 30.05$ million $/ \mathrm{ml})$ were found in group III; that is, the one that had a higher temperature gradient (by approximately $0.1-2.5^{\circ} \mathrm{C}$ ) than the other groups, with a lower amount of anomalous sperm 
( $7.72 \pm 0.77 v s .11 .43 \pm 1.28 \%$ in group II) than the buffaloes in group I that had a thinner TTC. This finding may reflect the fact that these animals showed greater scrotal heat loss and better thermoregulation. Increased thickness of the scrotum covering can be associated with depositions of fatty tissue that act as an insulator, suppressing testicular thermoregulation by reducing the amount of heat that can be irradiated from the scrotum (Coulter et al 1997; Yadav et al 2019).

Since testicular temperatures should be $4-6^{\circ} \mathrm{C}$ below core body temperatures to prevent damage to the testicular parenchyma (Garcia et al 2010; Kastelic, 2014), the authors concluded that the buffaloes with better scrotal thermoregulating capacity produced semen with better quality sperm. For this reason, it is important to impede the presence of factors that reduce thermal comfort (Kastelic and Brito, 2012; Santos et al 2014). This work shows that scrotal thermography, together with measurements of the scrotal circumference and TTC can be utilized to evaluate the quality of semen produced by buffaloes (Luzi et al 2013; Malama et al 2013).

\section{Diagnosing estrus}

One difficulty that dairy production has long had to deal with is the inadequate detection of estrus, which results in low reproductive yield (Verma et al 2014). Behavioral manifestations have played a vital role in identifying this condition, but female buffaloes only express these characteristic behaviors when a male is close by (Selvam and Archunan, 2017). Several proposals have been put forth as means of identifying estrus in individual female buffaloes (Selvam and Archunan, 2017), including biochemical and gynecological approaches, and close observation of visual parameters (e.g. frequency of miction, the texture of the vaginal mucous). The problem is that detecting and evaluating estrus using any of these parameters may entail higher costs and investments in time. For this reason, there is a very real need for new options capable of accurately detecting estrus. The study by Napolitano et al (2020) is one that has addressed the implementation of new reproductive technologies.

De Ruediger et al (2018) conducted a study of 40 female Murrah buffaloes with a corporal condition of $3.6 \pm 0.3$ (range: 1-5). They analyzed temperature variations in the muzzle, orbital area and vulva, progesterone concentrations (P4) during the follicular and luteal phases of the estrous cycle, and the influence of climate on female buffaloes treated with a hormonal protocol designed to synchronize the time of ovulation. Their central aim was to assess whether changes in microcirculation detected by IRT can be employed as a method for detecting estrus, given that female buffaloes do not express homosexual behaviors that might aid in detection (Singh et al 2000; Hockey et al 2010). The hormonal protocol was divided into two phases, as follows: phase 1: insertion of a P4-releasing intravaginal device with $2 \mathrm{mg}$ of benzoate of estradiol; phase 2: administration of prostaglandin F2 alpha and $400 \mathrm{UI}$ of equine chorionic gonadotropin, 9 days later, followed by treatment with GnRH on day 11 . Once this procedure began, blood samples were drawn and ultrasonography performed every day in the afternoon. These parameters were complemented by recording meteorological data and thermographic images of the muzzle, vulva, and orbital region every morning and afternoon, followed by measuring rectal temperature. This study found a moderateto-strong correlation between the thermal windows and plasma cortisol concentrations (orbital: 0.69; muzzle: 0.54; vulva: 0.42 ). In contrast, upon analyzing the relation between the concentration of $\mathrm{P} 4$ and the surface temperature of the vulva, strong negative correlations emerged $(-0.70)$, thus corroborating the hypothesis that the surface temperature of the vulva decreases as P4 increases in the plasma, as Sykes et al proposed (2012). Correlations for the surface temperature of the muzzle and orbital region were also negative, but weak (-0.24 and -0.29 , respectively). Scolari et al (2011) and Talukder et al (2014) mention that temperature variation in the vulva is likely due to the changes in blood progesterone and estrogen concentrations that occur during the estral cycle and may produce alterations of blood circulation in the vulva.

Although their approach did not prove efficacious in diagnosing estrus, it did demonstrate that thermographic images of the orbital region, muzzle and vulva accurately reflect rectal temperature quickly and non-invasively, and so can be used to study thermal comfort in river buffalo cows. Those authors further showed that the surface temperature of the vulva, specifically, is effective in determining the physiological changes inherent in variations in progesterone concentrations during the river buffalo's reproductive cycle (de Ruediger et al 2018).

\section{Health of the udder of dairy buffaloes}

Thermographic evaluation of the udder is becoming more frequent as a practice in studies conceived to evaluate the health of dairy cows, especially the relation between the surface temperature of the udder and scores obtained on the California test. Results suggest that IRT functions very well as a tool for detecting mastitis (Colak et al 2008).

The association between thermal mammary parameters and hormone concentrations in female buffaloes in different physiological stages has been an object of study by Chacur et al (2018), who used 24 female mestizo Murrah buffaloes divided into groups as follows: calves ( 8 months old), heifers (20 months), gestating (32 months), and lactating (56 months), with six individuals per group and a study duration of 4 months. Every 28 days, rectal temperature was taken and thermographic images of the udder (corpus mammae) were obtained, including the cranial and caudal cisterns, and from 
the cranial to the caudal teats. Blood samples were drawn to determine plasma progesterone concentrations, a factor similar to type I insulin, insulin, growth hormone, and estradiol.

The surface temperature of the cranial and caudal cisterns was higher in the groups of calves and heifers (Chacur et al 2018), a finding that coincides with reports in the literature which mention that adult females have a higher proportion of adipose tissue in the mammary structure (Hovey and Aimo, 2010) that could act as a form of thermal insulation and, therefore, impede heat dissipation through the skin. Observations of the group of gestating buffaloes showed a correlation between rectal temperature and the temperature of the cranial-to-caudal teats that, in turn, was linked to the temperature of the cranial and caudal cisterns. This demonstrates the existence of a relation between temperature variations and the evolution of the physiological demands of the udder (Chacur et al 2018), given that the end of the gestation period is a stage of intense mammary development marked by greater vascularization and higher temperatures (Prosser et al 1996; Davidson and Stabenfeldt, 2014). Another important finding involved the group of lactating buffaloes (Chacur et al 2018), where results show lower temperatures in the rectum and on the surface of the cranial cistern, likely related to the reduced metabolic activity and blood flow that occur during mammary involution and result in lower milk production (Capuco and Akers, 1999).

These results provide evidence of the existence of a connection between body temperature and the surface temperature of the udder that obeys the metabolic demands of both, and that can be studied using IRT (Chacur et al 2018), though it is necessary to keep in mind that temperatures can vary depending on the exact region of the udder evaluated, as shown in Figure 3. The thermograms in Figure 4 were taken immediately after automatic mechanical milking. It is also important to consider that, at least in cattle, the surface temperature of the caudal region of the udder by IRT may differ on occasions, and generally be higher (by $0.2-0.9{ }^{\circ} \mathrm{C}$ ) than lateral readings. Finally, the temperature of the lateral udder can vary significantly depending on the season of the year and the reproductive stage (Deak et al 2019).

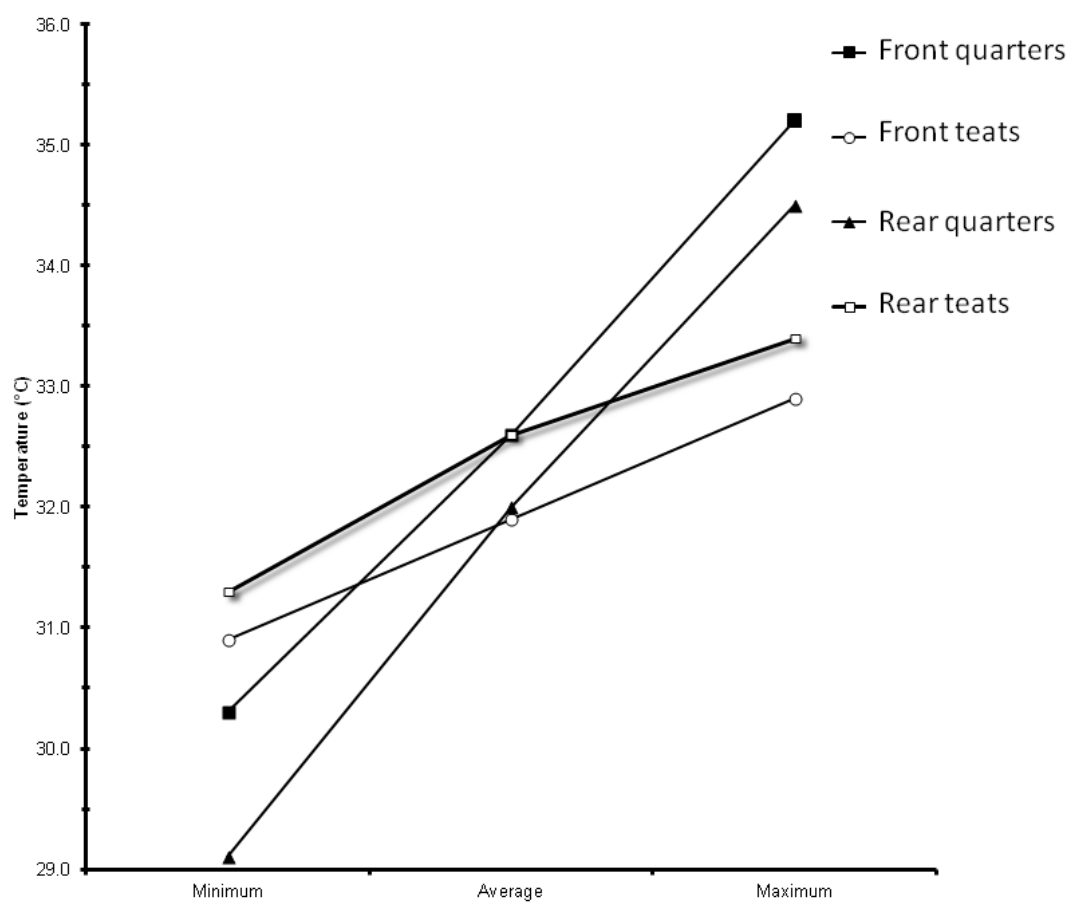

Figure 3 The surface temperature of distinct regions of the udder of dairy buffaloes. The surface temperature of the front quarters is higher than readings from the rear quarters $\left(32.6\right.$ vs. $\left.32^{\circ} \mathrm{C}\right)$, while the surface temperature of the rear teats is higher than that of the front ones $(32.6$ vs. $31.9^{\circ} \mathrm{C}$ ). Despite these differences, observations show that the temperatures of all four quarters behave similarly, have minimum temperatures lower than that of the teats, and maximum temperatures higher than those of the teats.

\section{Surface temperature of female buffaloes during milking}

According to Sevegnani et al (2016), dairy river buffalo cows that are held in waiting rooms before milking can experience a period of stress due to exposure to high temperatures during the waiting period when the shade is rarely provided. Given this species' deficient thermoregulating capacity, these conditions can affect their indices of production; thus, it seems essential to develop thermographic studies during the milking routine. Figure 5 shows the average surface temperatures of different thermal windows in 20 river buffalo cows held in paddocks in a humid tropical area of Mexico. IRT measurements covered the entire 
manual milking routine, including the following stages: the wait in the paddock, before entering the milking room, before milking, and immediately after milking (Figure 5). Readings show that the lowest surface temperatures, regardless of stage, were found on the flank and in the lacrimal caruncle.
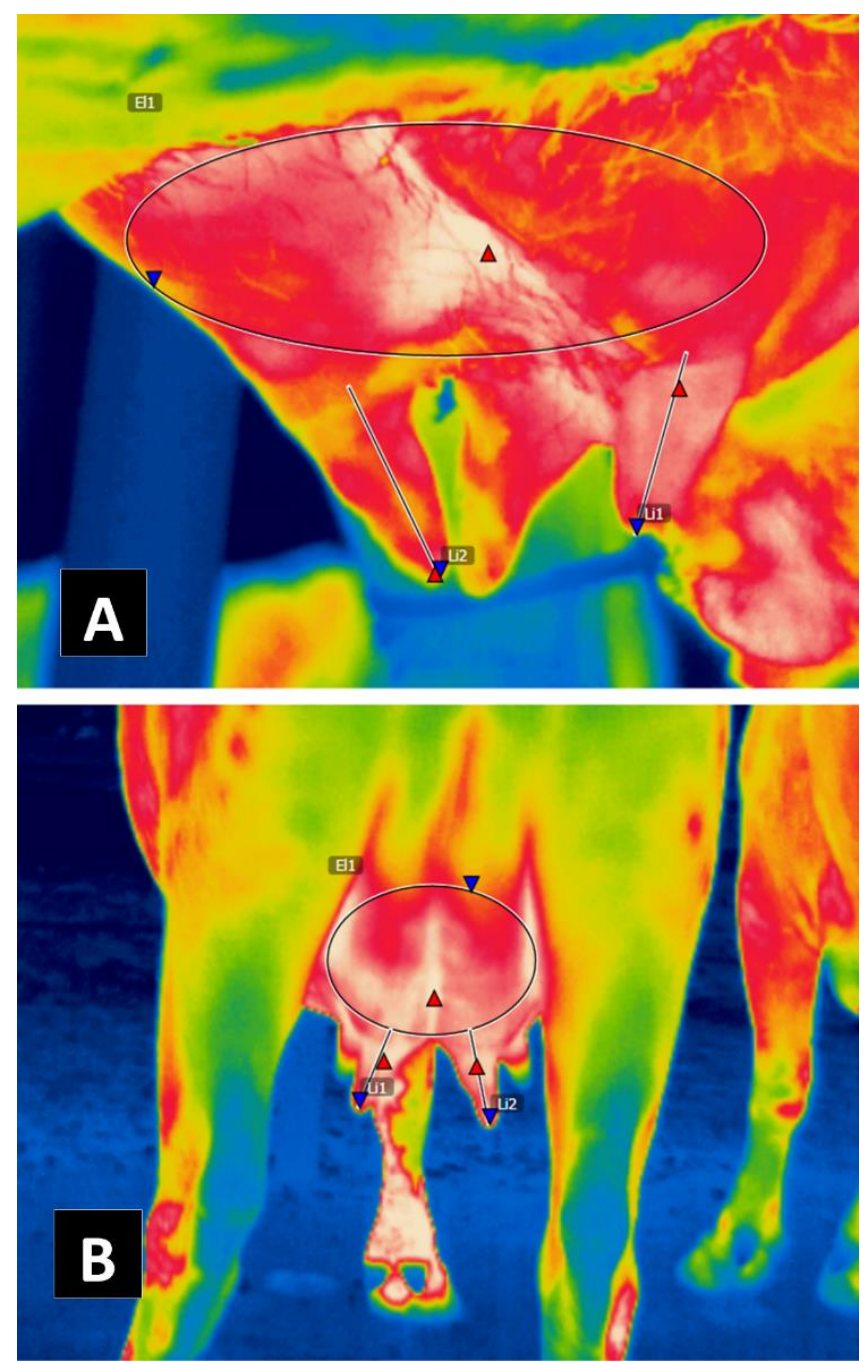

Figure 4 Thermograms of the left lateral (A) and caudal (B) regions of the udder of river buffalo cows immediately after automatic mechanical milking. Observe the areas with a whitish coloration that represents the high-temperature zones (around $34^{\circ} \mathrm{C}$ ) and cover $30 \%$ of the surface of the front quarters and $50 \%$ of the front teats. In contrast, observe that in the rear quarters these areas cover $60 \%$ of the surface and $80 \%$ of the rear teats. The presence of higher temperatures in the caudal area of the mammary quarters coincides with observations in dairy bovines raised under tropical conditions (Deak et al 2019).

It is clear that the temperatures with the least fluctuation were those of the periocular region and lacrimal caruncle; areas that, as mentioned above, are less subject to interference by ambient temperature (Barros et al 2016; de Ruediger et al 2018). One might say that the average temperatures obtained through the different thermal windows all show the same tendency; that is, a decrease after entering the milking room, an increase during stimulation by the calf, and again when milking begins and, finally, a decrease that lowers the temperature to around the level recorded in Stage 1. It is important to note, however, that the temperature of the flank, muzzle, and auricular pavilion does not always show this tendency. In the case of the flank, the influence of ambient temperature (Martello et al 2010; Barros et al 2016) might generate an increase of $1{ }^{\circ} \mathrm{C}$ in Stage 2 ; however, more detailed analyses are required to determine whether the temperature decreases recorded in these three thermal windows during Stage 4 are due to a redistribution of dermal microcirculation towards the udder that is stimulated during milking.

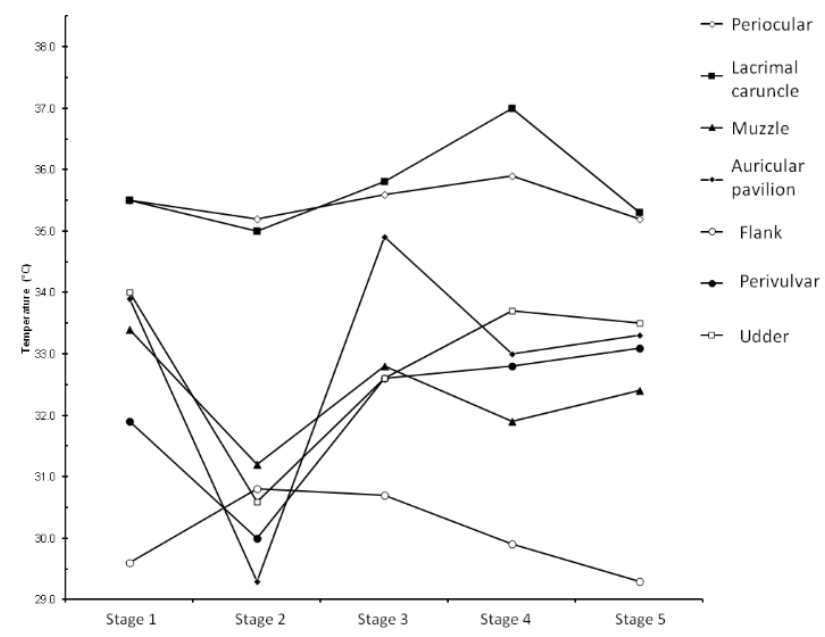

Figure 5 Thermal changes registered by IRT in the periocular region, lacrimal caruncle, muzzle, auricular pavilion, flank, perivulvar area, and udder of water buffalo cows throughout the manual milking routine. Stage 1: before entering the milking room; Stage 2: before stimulation by the calf; Stage 3: during stimulation by the calf; Stage 4: during milking; Stage 5: after milking.

\section{Final Considerations}

Scientific evidence demonstrates that, as with other species, IRT and various thermal windows of the buffalo can be utilized to evaluate physiological processes quickly and non-invasively. The temperature of the orbital area, muzzle and vulva have proven to be efficient for evaluating thermal comfort, an aspect of prime importance in this species given the adverse climatic conditions in which it is raised, coupled with its limited thermoregulating capacity under constant exposure to the extreme temperatures of humid tropical regions. In male buffaloes, measuring scrotal temperature seems to be an appropriate tool for evaluating semen quality, while in females the surface temperature of the udder has proven useful in evaluating mammary development. Both of these aspects are of great zootechnical importance.

In conclusion, considering the recent nature of studies of these topics in this species that, despite its characteristic rusticity, can be affected by environmental variation, we recommend continuing research on the use of IRT as a complementary technique in reproductive examinations to 
determine to what extent it can be used to detect estrus, as this would be of enormous utility for production systems. Likewise, we expect that thermographic studies designed to evaluate the welfare of buffaloes will continue to be performed because the knowledge generated can contribute to the development of solutions to problems that currently affect both animal welfare and production.

\section{Conflict of Interest}

The authors declare that they have no conflict of interest.

\section{Funding}

This research did not receive any financial support.

\section{References}

Aggarwal A, Upadhyay R (2013) Thermoregulation. In: Aggarwal A, Upadhyay R (eds) Heat Stress and Animal Productivity, 1 st edn. Springer, India, pp. 1-25.

Alsaaod M, Büscher W (2012) Detection of hoof lesions using digital infrared thermography in dairy cows. Journal Dairy Science 95:735742.

Andrade D (2015) Thermal windows and heat exchange. Temperature 2:451.

Angulo R, Noguera R, Berdugo JA (2005) El búfalo de agua (Bubalus bubalis) un eficiente utilizador de nutrientes: aspectos sobre fermentación y digestión ruminal. Livestock Research for Rural Development 17:67-71.

Barboza J (2011) Bondades ecológicas del búfalo de agua: camino hacia la certificación. Tecnología en Marcha 24:82-88.

Barros DV, Silva LKX, Kahwage PR, Lourenço- Junior JB, Sousa JS, Silva AGM, Franco IM, Martorano LG, Garcia AR (2016) Assessment of surface temperatures of buffalo bulls (Bubalus bubalis) raised under tropical conditions using infrared thermography. Arquivo Brasileiro de Medicina Veterinária e Zootecnia 68:422-430.

Bertoni A, Napolitano F, Mota-Rojas D, Sabia E, Alvarez-Macias A, Mora-Medina P, Morales CA, Berdugo GJA, Guerrero-Legarreta I (2020) Similarities and differences between river buffaloes and cattle: health, physiological, behavioural and productivity aspects. Journal of Buffalo Science 9:92-109.

Brcko CC, Da Silva JAR, Martorano LG, Vilela RA, Nahúm B, Silva AG, Barbosa AV, Bezerra AS, Lourenco J (2020) Infrared thermography to assess thermoregulatory reactions of female Buffaloes in a humid tropical environment. Frontiers in Veterinary Science 7:180.

Capuco AV, Akers RM (1999) Mammary involution in dairy animals. Journal of Mammary Gland Biology and Neoplasia 4:137144.

Casas-Alvarado A, Mota-Rojas D, Hernández-Ávalos I, MoraMedina P, Olmos-Hernández A, Verduzco-Mendoza A, MartínezBurnes J (2020) Advances in infrared thermography: surgical aspects, vascular changes and pain monitoring in veterinary medicine. Journal of Thermal Biology 92: doi.org/10.1016/j.jtherbio.2020.102664.

Chacur MGM, Bastos GP, Vivian DS, Silva L, Chiari LNF, Araujo JS, Souza CD, Gabriel- Filho LRA (2016) Use of infrared thermography to evaluate the influence of the climatic factors in the reproduction and lactation of dairy cattle. Acta Scientiae Veterinaria 44:1412-1421.

Chacur MGM, Dantas A, Oba E, Ruediger FR, Oliveira RA, Bastos GP, Jorge AM (2018) Avaliação termográfica do desenvolvimento mamário de búfalas e suaregulação endócrina em distintos estágios fisiológicos. Arquivo Brasileiro de Medicina Veterinária e Zootecnia $70: 450-456$.

Clapper JA, Ottobre JS, Ottobre AC, Zartman DL (1990) Estrual rise in body temperature in the bovine I. Temporal relationships with serum patterns of reproductive hormones. Animal Reproduction Science 23:89-98.

Cravello B, Ferri A (2008) Relationships between skin properties and environmental parameters. Skin Research and Technology 14:180186.

Colak A, Polat B, Okumus Z, Kaya M, Yanmaz LE, Hayirli A (2008) Short communication: early detection of mastitis using infrared thermography in dairy cows. Journal Dairy Science 91:4244-4248.

Coulter GH, Cook RB, Kastelic JP (1997) Effects of dietary energy on scrotal surface temperature, seminal quality, and sperm production in young beef bulls. Journal Animal Science 75:10481052.

Davidson PA, Stabenfeldt HG (2014) A glândula mamária. In: Klein GB (ed) Cunningham tratado de fisiología veterinária, 5th edn. Elsevier, Rio de Janeiro, pp 439-449.

De Ruediger FR, Yamada PH, Bicas-Barbosa LG, Chacur MGM, Pinheiro-Ferreira JC, De Carvalho NAT, Milani-Soriano GA, Codognoto VM, Oba E (2018) Effect of estrous cycle phase on vulvar, orbital area and muzzle surface temperatures as determined using digital infrared thermography in buffalo. Animal Reproduction Science 197:154-161.

Deak FLGB, Chacur MGM, Souza CD, Andrade IB, Cornacini GF, Garcia AR, Gabriel-Filho LRA (2019) Effects of physiological stage and season on infrared thermograms of different body areas of dairy cows raised under tropical conditions. Animal Reproduction 16:311316.

Fisher AD, Morton R, Dempsey JM, Henshall JM, Hill JR (2008) Evaluation of a new approach for the estimation of the time of the LH surge in dairy cows using vaginal temperature and electrodeless conductivity measurements. Theriogenology 70:1065-1074.

Flores-Peinado S, Mota-Rojas D, Guerrero-Legarreta I, MoraMedina P, Cruz-Monterrosa R, Gómez J, Hernández MA, CruzPlayas J, Martínez J (2020) Pre-slaughter stress in pigs, infrared thermography assessment and meat quality. International Journal of Veterinary Science and Medicine (In review).

Garcia OS, Vale WG, Garcia AR, Ribeiro HFL, Ferro RS, RolimFilho ST, Sousa EM (2010) Experimental study of testicular insulation in buffalo. Revista Veterinaria 21:889-891.

Gloster J, Ebert K, Gubbins S (2011) Normal variation in thermal radiated temperature in cattle: implications for foot-and-mouth disease detection. BMC Veterinary Research 7:73.

Guerrero-Legarreta I, Napolitano F, Cruz-Monterrosa RG, MotaRojas D, Mora-Medina P, Ramírez-Bribiesca E, Bertoni A, Berdugo GJ, Braghieri A (2020) River buffalo meat production and quality: sustainability, productivity, chemical composition and sensory properties. Journal of Buffalo Science 9: (Accepted).

Hockey CD, Morton JM, Norman ST, Mcgowan MR (2010) Evaluation of a neck mounted 2-hourly activity meter system for 
detecting cows about to ovulate in two paddock-based Australian dairy herds. Reproduction in Domestic Animals 45:107-117.

Hoffmann G, Schmidt M, Ammon C (2013) Monitoring the body temperature of cows and calves using video recordings from an infrared thermography camera. Veterinary Research Communicatioin 37:91-99.

Hovey RC, Aimo L (2010) Diverse and active roles for adipocytes during mammary gland growth and function. Journal of Mammary Gland Biology and Neoplasia 15:279-290.

Kastelic JP (2014) Understanding and evaluating bovine testes. Theriogenology 81:18-23.

Kastelic JP, Brito LF (2012) Ultrasonography for monitoring reproductive function in the bull. Reproduction in Domestic Animals 47:45-51.

Kastelic JP, Rizzoto G, Thundathil J (2018) Review: Testicular vascular cone development and its association with scrotal thermoregulation, semen quality and sperm production in bulls. Animal 12:133-141.

Knizkova I, Kunc P, Gurdil GAK, Pinar Y, Selvi KC (2007) Applications of infrared thermography in animal production. Journal of the Faculty of Agriculture 22:329-336.

Kyle BL, Kennedy AD, Small JA (1998) Measurement of vaginal temperature by radiotelemetry for the prediction of estrus in beef cows. Theriogenology 49:1437-1449.

Lunstra DD, Coulter GH, (1997) Relationship between scrotal infrared temperature patterns and natural-mating fertility in beef bulls. Journal of Animal Science 75:767-774.

Luzi F, Mitchell M, Costa LN, Redaelli V (2013) Thermography: current status and advances in livestock animals and in veterinary medicine. Fondazione Iniziative Zooprofilattiche e Zootecniche Brescia. http://www.fabioluzi.it/wordpress/wpcontent/uploads/2012/11/092-2013-Thermography-current-statusand-advances-in-livestock-animals-and-in-veterinary-medicine-1Copia.pdf Accessed on: February 3, 2020.

Malama E, Bollwein H, Taitzoglou IA, Theodosiou T, Boscos CM, Kiossis E (2013) Chromatin integrity of ram spermatozoa. Relationships to annual fluctuations of scrotal surface temperature and temperature-humidity index. Theriogenology 80:533-541.

Martello LS, Savastano-Junior H, Silva SL, Balieiro JCC (2010) Alternative body sites for heat stress measurement in milking cows under tropical conditions and their relationship to the thermal discomfort of the animals. International Journal of Biometeorology $54: 647-652$

Menegassi SRO, Pereira GR, Dias EA, Rocha MK, Carvalho HR, Koetz-Junior C, Oberst ER, Barcellos JOJ (2018) Infrared thermography as a noninvasive method to assess scrotal insulation on sperm production in beef bulls. Andrologia 50:12904.

Montanholi YR, Odongo NE, Swanson KC, Schenkel FS, McBride BW, Miller SP (2008) Application of infrared thermography as an indicator of heat and methane production and its use in the study of skin temperature in response to physiological events in dairy cattle (Bos taurus). Journal of Thermal Biology 33:468-475.

Mora-Medina P, Berdugo-Gutiérrez J, Mota-Rojas D, Nava AJ, Guerrero-Legarreta I, (2018a) Behaviour and welfare of dairy buffaloes: pasture or confinement? Journal of Buffalo Science 7:4348.

Mora-Medina P, Napolitano F, Mota-Rojas D, Berdugo-Gutiérrez J, Ruiz-Buitrago J, Guerrero-Legarreta I, (2018b) Imprinting, sucking and allosucking behaviors in buffalo calves. Journal of Buffalo Science 7:49-57.

Mosher MD, Ottobre JS, Haibel GK, Zartman DL (1990) Estrual rise in body temperature in the bovine II. The temporal relationship with ovulation. Animal Reproduction Science 23:99-107.

Mota-Rojas D, Orihuela A, Strappini-Asteggiano A, Cajiao-Pachón MN, Aguera-Buendia E, Mora-Medina P, Ghezzi M, AlonsoSpilsbury SM, (2018) Teaching animal welfare in veterinary schools in Latin America. International Journal of Veterinary Science and Medicine 6:131-140.

Mota-Rojas D, De Rosa G, Mora-Medina P, Braghieri A, GuerreroLegarreta I, Napolitano F (2019) Invited review: Dairy buffalo behaviour and welfare from calving to milking. CAB Reviews 14:19.

Mota-Rojas D, Napolitano F, Bertoni A, Gómez PJ, Mora-Medina P, Cruz-Monterrosa R, Álvarez-Macías A, Pérez NJ, GuerreroLegarreta I (2020a) Thermal biology in river buffalo in the humid tropics: neurophysiological and behavioral responses. International Journal of Veterinary Science and Medicine (In review).

Mota-Rojas D, Broom DM, Orihuela A, Velarde A, Napolitano N, Alonso-Spilsbury M (2020b) Effects of human-animal relationship on animal productivity and welfare. Journal of Animal Behaviour and Biometeorology 8:196-205.

Mota-Rojas D, Olmos-Hernández A, Verduzco-Mendoza A, LeconaButrón H, Martínez-Burnes J, Mora-Medina P, Gómez PJ, Orihuela A, (2020c) Infrared thermal imaging associated with pain in laboratory animals. Experimental Animals 69: (Accepted).

Napolitano F, Serrapica F, Braghieri A, Masucci F, Sabia E, De Rosa G, (2019) Human-Animal Interactions in Dairy Buffalo Farms. Animals 9:246.

Napolitano F, Arney D, Mota-Rojas D, De Rosa G, (2020) Chapter 17. Reproductive Technologies and Animal Welfare. In: Reproductive Technologies in animals. Giorgio A. Presicce (Eds). S\&T Sci., Elsevier Press, London, United Kingdom. pp. 275-286.

Orihuela A, Mota-Rojas D, Velarde A, Strappini-Asteggiano A, Thielo de la Vega L, Borderas-Tordesillas F, (2018) Invited review: environmental enrichment to improve behaviour in farm animals. CAB Reviews 13:1-25.

Paim TP, Borges BO, Lima PMT, Gomes EF, Dallago BSL, Fadel R, Menezes AM, Louvandini H, Canozzi MEA, Barcellos JOJ, McManus C (2013) Thermographic evaluation of climatic conditions on lambs from different genetic groups. International Journal of Biometeorology 57:59-66.

Peng D, Chen S, Li G, Chen J, Wang J, Gu X (2019) Infrared thermography measured body surface temperature and its relationship with rectal temperature in dairy cows under different temperature-humidity indexes. International Journal of Biometeorology 63:327-336.

Pérez-Pedraza E, Mota-Rojas D, González-Lozano M, GuerreroLegarreta I, Martínez-Burnes J, Mora-Medina P, RamírezNecoechea R (2018) Infrared thermography and metabolic changes in castrated piglets due to the effects of age and the number of incisions in the testicles. American Journal of Animal and Veterinary Sciences 13:104-114.

Prosser CG, Davis SR, Farr VC, Lacasse P (1996) Regulation of blood flow in the mammary microvasculature. Journal Dairy Science 79:1184-1197. 
Purohit RC, Hudson RS, Riddell MG, Carson RL, Wolfe DF, Walker DF (1985) Thermography of the bovine scrotum. American Journal of Veterinary Research. 46:2388-2392.

Redden KD, Kennedy AD, Ingall SJR, Gilson TL (1993) Detection of estrus by radiotelemetric monitoring of vaginal and ear skin temperature and pedometer measurements of activity. Journal Dairy Science 76:713-721.

Romanovsky AA, Ivanov AI, Shimansky YP (2002) Selected Contribution: Ambient temperature for experiments in rats: a new method for determining the zone of thermal neutrality. Journal of Applied Physiology 92:2667-2679.

Ruiz LG, Castro RV, Cordoba IA, Castillo GA, Jayme AV, Rosas SL (2012) El sistema nervioso autónomo: un enfoque integral y dialéctico para el estudiante universitario. Universidad Autónoma Metropolitana. CBS.

Santos AX, Kahwage PR, Faturi C, Quinzeiro NT, Lourenço-Junior JB, Joele MRSP, Garcia AR (2014) Feed supplementation with palm kernel cake-based concentrate increases the quality of water buffalo semen. Animal Reproduction 11:85-95.

Scolari SC, Clark SG, Knox RV (2011) Vulvar skin temperature changes significantly during estrus in swine as determined by digital infrared thermography. Journal of Swine Health and Production 19:151-155

Selvam RM, Archunan G (2017) A combinatorial model for effective estrus detection in murrah buffalo. Veterinary World 10:209-213.

Sevegnani KB, Fernandes DPB, Silva SHMG (2016) Evaluation of thermoregulatory capacity of dairy buffaloes using infrared thermography. Engenharia Agrícola 36:1-12.

Singh J, Nanda AS, Adams GP (2000) The reproductive pattern and efficiency of female buffaloes. Animal Reproduction Science 60:593-604.
Stewart M, Webster JR, Stafford KJ, Schaefer AL, Verkerk GA (2010) Technical note: effects of an epinephrine infusion on eye temperature and heart rate variability in bull calves. Journal Dairy Science 93:5252-5257.

Sykes DJ, Couvillion JS, Cromiak A, Bowers S, Schenck E, Crenshaw M (2012) The use of digital infrared thermal imaging to detect estrus in gilts. Theriogenology 78:147-152.

Talukder S, Kerrisk KL, Ingenhoff L, Thomson PC, Garcia SC, Celi $P$ (2014) Infrared technology for estrus detection and as a predictor of time of ovulation in dairy cows in a pasture-based system. Theriogenology 81:925-935.

Tattersall GJ (2016) Infrared thermography: A non-invasive window into thermal physiology. Comparative Biochemistry and Physiology Part A: Molecular \& Integrative Physiology 202:78-98.

Tattersall GJ, Cadena V (2010) Insights into animal temperature adaptations revealed through thermal imaging. The Imaging Science Journal 58:261-268.

Tortora GJ, Derrickson B (2013) Metabolismo y Nutrición. In: Tortora GJ, Derrickson B (eds) Principios de anatomía y fisiología, 13 edn. Médica Panamericana, España, pp. 1048-1051.

Travain T, Colombo ES, Heinzl E, Bellucci D, Previde EP, Valsecchi $P$ (2015) Hot dogs: Thermography in the assessment of stress in dogs (Canis familiaris) - A pilot study. Journal of Veterinary Behavior 10:17-23.

Verma KK, Prasad S, Mohanty TK, Kumaresan A, Layek SS, Patbandha TK, Kantwa SC (2014) Behavioural signs of estrus in different parity of Murrah buffaloes (Bubalus bubalis): a comparative study. Indian Journal of Animal Research 48:620-624.

Yadav SK, Singh P, Kumar P, Singh SV, Singh A, Kumar S (2019) Scrotal infrared thermography and testicular biometry: Indicator of semen quality in murrah buffalo bulls. Animal Reproduction Science 209:106145. doi.org/10.1016/j.anireprosci.2019.106145 